\title{
Nas origens da vontade de potência: Anaxágoras*
}

\author{
Stefano Busellato**,***
}

Resumo: O presente artigo estuda a interpretação nietzschiana de um pré-socrático pouco considerado pela literatura secundária: Anáxagoras de Clazômenas. São evidenciados alguns elementos da completa originalidade interpretativa de Nietzsche com relação à tradicional exegese do filósofo grego, como, por exemplo, a leitura do Nous em termos materialistas, a explicação do nascimento das qualidades de disposições quantitativas ou interpretar as homeomerias anaxagorianas como pontos de força. Dessas e de outras características da leitura nietzschiana de Anaxágoras emergem aspectos específicos que se encontrarão adiante na teoria da Vontade de potência, teoria, portanto, que possui, na interpretação de Anaxágoras, a primeira elaboração teórica.

Palavras-chave: Anaxágoras, Vontade de potência, ontologia antiga.

* Traduzido do italiano para o português por Anna Maria Lorenzoni.

** Universidade Estadual do Oeste do Paraná, Cascavel, Paraná, Brasil.

*** Universidade Federal da Integração Latino-Americana (UNILA), Foz do Iguaçu, Paraná, Brasil. ORCID https://orcid.org/0000-0002-8737-6267

Correio eletrônico: stefano.busellato@gmail.com 
Busellato, S.

$\S 1$. Querer se aproximar do significado de Vontade de Potência significa adentrar-se em uma das zonas mais intrincadas do pensamento nietzschiano. Zona na qual, mais do que em qualquer outro lugar, são necessárias paciência e cautela.

Frequentemente mencionada junto a outras concepções que tornaram Nietzsche célebre - o Eterno retorno, o Übermensch, o Amor fati - a vontade de potência, na verdade, é bem diversa delas, seja pela história, seja pelas características. Se aquelas concepções podem ser bem delimitadas em porções cronológicas ou em obras precisas, a vontade de potência se expande à quase totalidade da reflexão nietzschiana. Começa a aparecer, em graus diversos de elaboração e bem antes de encontrar a própria estabilidade terminológica, nas anotações de $1882^{1}$, e, publicamente, na parte II de Zaratustra ${ }^{2}$, para, após, ampliar-se até as inumeráveis ocorrências da segunda metade dos anos oitenta, sobretudo no material póstumo, que deveria ter se condensado na projetada e depois abandonada obra homônima ${ }^{3}$.

Foram muitos os estudos que mostraram, nas leituras dos textos científicos, sobretudo daqueles que tratavam do conceito físico e biológico de força $(K r a f t)$, o terreno a partir do qual a vontade de potência tomou forma conceitualmente. Nisso, foram decisivos autores como Boscovich e os seus pontos de força, Mayer

1 A primeira ocorrência da locução pode ser identificada no fragmento NF-1882,5[1] de novembro de 1882 - fevereiro de 1883, KSA 10.187. De fato, ela aparece em dois fragmentos que o precedem (o NF-1876, 23[63], fim de 1876 - verão de 1877, KSA 8.425 e o NF-1880,4[239] - verão de 1880, KSA 9.159), mas apenas como expressão verbal privada dos conteúdos que terá em seguida.

$2 \mathrm{Um}$ dos textos mais significativos para ilustrar o tortuoso caminho que Nietzsche percorreu para finalmente atingir a formulação conclusiva do filosofema é Aurora, no qual encontramos Wolluiste der Macht [vontade de potência] (M/A 113; KSA 3.103); Machtgefühl [sentimento de potência] (M/A 140, 189, 356, 360; KSA 3.132, 162, 240, 241); Gefiuhle der Macht, [senso de potência] (M/A 189, 245, 348, 403; ; KSA 3.162, 204, 238, 253); Machtgelüst [libido de potência] (M/A 199, 204; KSA 3.174, 180), Liebe zur Macht [amor à potência] (M/A 262; ; KSA 3.209).

3 Texto que, não obstante jamais tenha sido escrito por Nietzsche, ainda aparece nas livrarias. Sempre útil, portanto, Montinari (1996).

106 | Cad. Nietzsche, Guarulhos/Porto Seguro, v.42, n.2, p. 105-124, maio/agosto, 2021. 
e o Auslösung von Kraft (desencadeamento de força), Wilhelm Roux e o seu agonismo fisio-biológico, Johan Gustav Vogt ${ }^{4}$ e a sua visão de força não mais em dualismo com a matéria e capaz de ultrapassar as teorias mecanicistas.

Entretanto, se o conjunto desses estudos tem o grande mérito de especificar a real direção de uma leitura correta da vontade de potência, distanciando-a dos equívocos de caráter metafísico, político ou das interpretações mais superficiais e desajeitadamente musculosas, deter-se em tais estudos pode acarretar uma subestimação ou uma ocultação de importantes matrizes puramente filosóficas da concepção nietzschiana.

Ao querer evidenciar as fontes científicas que nutriram o pensamento de Nietzsche, deve-se, de fato, ter em mente que Nietzsche não era um cientista e que, devido a isso, os elementos que ele extrai das próprias leituras da Naturwissenschaft passam necessariamente por uma alteração gnosiológica: de componentes científicos, tais elementos tornam-se metáforas filosóficas. Seja porque falta a Nietzsche uma preparação técnica necessária para se firmar no interior de um discurso puramente científico; seja porque seu real interesse era sair desse meio, dele colhendo elementos que depois poderiam ser utilizados em âmbitos alheios àqueles originalmente científicos, alargando-os, portanto, à reflexão ética, antropológica, existencial, ontológica, estética, ou seja, em poucas palavras - à reflexão filosófica.

Dando atenção a essa passagem - da especificidade científica à amplitude filosófica - surge, então, a necessidade de um olhar interpretativo sobre a Wille zur Macht que vá em busca de um terreno

4 Sobre Boscovich, veja-se Gori (2007a); sobre Mayer, veja-se Alwin Mittasch, Nietzsche als Naruralphilosoph, Kröner, Struttgart 1952, cap. 12-13; sobre Roux, veja-se Müller-Lauter (1974); Müller-Lauter (1978); Orsucci (1992); sobre Vogt, veja-se Bauer (1984). Para uma rápida contextualização da questão, veja-se Stack (1982); Gori (2007b). 
Busellato, S.

especificadamente filosófico sobre o qual ela se forma e que, apenas posteriormente, Nietzsche enriquecerá e elaborará por meio das especificações provenientes das fontes científicas.

Nesse terreno, podem ser rastreados percursos precisos marcados pela influência das filosofias que ele mais conhecia, sobretudo aquela schopenhaueriana da Wille zur Leben; as sugestões talvez de filósofos com os quais ele entrou em contato no momento de maior elaboração conceitual do próprio filosofema, por exemplo, o Espinosa do conatus; do Deus sive natura que, em Nietzsche, se tornará chaos sive natura; ou da dinâmica de aumento ou redução da potência do ser descrita na terceira parte da Ethica.

Porém, ainda mais, para analisar as origens filosóficas da Vontade de potência, é necessário, antes de tudo, voltar ao ponto do qual partiu a reflexão filosófica nietzschiana: o âmbito que certamente ele dominava com maior profundidade - a filosofia grega, especialmente aquela pré-platônica.

$\S 2$. Analisando os estudos que Nietzsche dedicou aos filósofos pré-platônicos, é de fato possível frequentemente deparar-se com passagens que parecem embriões conceituais daquilo que posteriormente será a figura madura da Vontade de potência. Não surpreende, portanto, que isso ocorra nas páginas dedicadas aos pré-socráticos mais apreciados por ele: Empédocles, Demócrito e, sobretudo, Heráclito.

Mas um caso igualmente interessante é representado por Anaxágoras, filósofo raramente incluído pela literatura secundária entre aqueles teoricamente importantes para Nietzsche. Preconceito estranho, este, que pede para ser dissipado à luz de elementos textuais 
precisos $^{5}$. Anaxágoras, de fato, é objeto de apreciação durante todo o arco do filosofar nietzschiano, a começar em 1871, onde é visto como representante da «liberdade de pensamento ateniense» (NF1871,16[17]; KSA 7.399) ${ }^{6}$, até março de 1887-novembro de 18887, quando é citado em oposição aos "sintomas de decadência" que surgem após Sócrates, trazendo "à tona os instintos anti-helênicos" e Anaxágoras é visto, em vez disso, como "ainda completamente helênico".

Lançando o olhar para o espaço que Nietzsche confia a Anaxágoras no interior de seu único escrito dedicado inteiramente ao pensamento pré-socrático, A filosofia na época trágica dos gregos, notamos que, a ele, são reservados 6 dos 19 parágrafos que compõem o texto, mais do que qualquer outro filósofo abordado, e tratam-se dos seis parágrafos conclusivos que, excluídos os dois primeiros introdutivos, representam mais de um terço de toda a obra - um sinal claro da importância que o pensador de Clazômenas teve para Nietzsche. Essa importância é confirmada também pelas lições sobre

5 Preconceito que pode ter se originado a partir do trecho mais célebre sobre Anaxágoras, encontrado no parágrafo 12 de $O$ nascimento da tragédia (KSA 1.87), no qual o Nous é comparado ao Deus ex machina de Eurípides, responsável por matar o espírito da tragédia ática. Entretanto, ao analisar-se o conjunto das referências a Anaxágoras, é possível notar, nessa passagem, unicamente uma razão retórica, não interpretativa. Nas demais ocasiões nas quais Nietzsche enfrenta essa questão, afirma precisamente o contrário: "Como é grande a injustiça para com Anaxágoras, quando é censurado da sua abstenção sábia em relação à teleologia, que se revela nesta concepção, e quando se fala do seu Nous com desdém, como se fora um deus ex machina!" (PHG/FT, 17 - trad. de Maria Inês Madeira

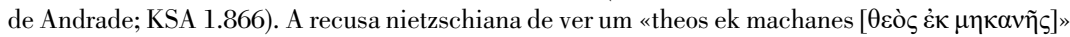
no Nous, repete-se também em Friedrich Nietzsche, Les pholosophes préplatoniciens, textes établis d'après les manuscrits par Paolo D'Iorio, éditions de l'éclat, Paris, 1994 (a esta edição, de agora em diante abreviada com a sigla VP, será feita referência ao número da página, §12, p. 190). No NF-1875,6 [46], KSA 8.114 fala-se, inclusive, do Nous como «ä $\vartheta \varepsilon o \varsigma$ ex machina». Para um dos poucos estudos sobre a interpretação anaxagoreana de Nietzsche, veja-se Claudia Rosciglione, Homo natura, autoregolazione e caos nel pensiero di Nietzsche, ETS Edizioni, Pisa 2005, especialmente as pp. 67-140.

6 Para outros dentre os mais significativos elogios a Anaxágoras, veja-se também NF-1872,21[15], KSA 7.527; NF-1872,21[16], KSA 7.527; NF-1872,23[8], KSA 7.541; NF-1872,23[22], KSA 7.547, PHG §17, p. 358; KSA 1.866.

7 NF-1887,11[375]; KSA 13.168

Cad. Nietzsche, Guarulhos/Porto Seguro, v.42, n.2, p. 105-124, maio/agosto, 2021. | 109 
Busellato, S.

os Filósofos pré-platônicos, nas quais Anaxágoras é referido como “o principal filósofo autenticamente grego" .

À primeira vista, pode parecer muito grande a distância que intercorre entre a visão anaxagoreana e as características que terá a Vontade de potência nietzschiana. Esta última é a tentativa de elaborar uma hipótese interpretativa unitária ${ }^{9}$ capaz de abarcar a natureza global da realidade (Wirklichkeit) tanto física, quanto biológica e psicológica. Recorrendo a um número mínimo de elementos explicativos, Nietzsche propõe um quadro radicalmente imanente e antimetafísico no qual a realidade se mostra como um processo dinâmico de incessantes conflitos entre elementos caracterizados por centros de força desiguais que se articulam agonicamente na vontade de expansão do próprio âmbito de domínio, em detrimento dos outros que opõem resistência. Nesse processo de mútua e conflituosa disputa, formam-se constelações de quanta de força que têm como objetivo englobar outros quanta de força exclusivamente para aumentar a própria potência (Machtsteigerung). A Vontade de potência diz respeito, portanto, a uma visão baseada unicamente sobre a multiplicidade e sobre a sua contínua transformação. A sua natureza é quantitativa (maior ou menor potência). Dela, as qualidades surgem como conformações de aglomerados quantitativos de forças. A unidade, portanto, é excluída, não passando de uma pluralidade organizada em formações provisórias que se movem em uma eterna dança de desagregação e recomposição, dando continuamente origem a novas agregações hierárquicas, instáveis e mutáveis. $\mathrm{O}$ ser, compreendido como permanência da unidade (Seingrund) é, assim, banido. Do mesmo modo como é banido todo e qualquer finalismo, dado que a vontade de expansão e crescimento é irracional, ou seja, privada $a b$ initio de uma motivação que inicie o processo,

$8 \mathrm{VP}$, p. 187.

9 Sobre a natureza hipotética da Vontade de potência de Müller-Lauter (1974), especialmente as pp. 137-140.

110 | Cad. Nietzsche, Guarulhos/Porto Seguro, v.42, n.2, p. 105-124, maio/agosto, 2021. 
e que atingirá um estado final (Finalzustand) no qual possa reinar um equilíbrio e uma ordem que significaria o cessar do vir-a-ser.

§3. O que isso tudo tem a ver com a visão cosmológica de Anaxágoras, a qual é tradicionalmente interpretada em termos de mesclagem de qualidades originárias (homeomerias) sobre as quais intervém a obra inteligente e consciente de um princípio imaterial, o Nous, que introduz ordem e racionalidade no existente? O fato é que Nietzsche apresenta uma leitura fortemente original de Anaxágoras, que se opõe precisamente à interpretação tradicionalmente dada a ele. $\mathrm{E}$, desenvolvendo a própria exegese, começa a elaborar alguns dos elementos mais importantes que posteriormente construirão a constelação conceitual da Vontade de potência.

Um Nous, compreendido metafisicamente como inteligência ordenadora, foi exatamente aquilo que - de Platão a Hegel, de Aristóteles a Schopenhauer - fez de Anaxágoras o primeiro "sóbrio em meio aos embriagados, que antes dele falavam ao acaso"10. Nietzsche, em vez disso, apresenta uma leitura oposta. Partindo da polissemia da língua grega, ele, antes de mais nada, sublinha que o Nous "não [é] exatamente a inteligência, nem o intelecto, nem a razão"11. Aliás, dar ao princípio anaxagoreano uma característica racional, ideal ou abstrata é o motivo pelo qual ele afirma que “todos

10 Aristóteles, Metafísica, 984b 14-15. Expressão retomada por Hegel no primeiro volume das Lições sobre História da Filosofia, "O primeiro período, a filosofia grega", para elogiar aquele no qual é possível ver por primeiro "o pensamento em geral, erguido em princípio", reconhecendo "como absoluto o voṽ, o pensar, o intelecto, a razão". A respeito da leitura de Platão sobre Nous como "inteligência que ordena e causa todas as coisas", veja-se Fed $97 \mathrm{c}$ et seq. Schopenhauer, seguindo essa interpretação, afirma que, dentre os filósofos, "meu antípoda direto é Anaxágoras» (WV, II, § 21), criticando, em numerosas passagens, seu racionalismo e otimismo (cfr. WV, II $\S \S 25,26,46)$. A leitura de Nietzsche, caminhando em direção bastante diversa, mostra-se original também com relação às interpretações de Anaxágoras de muitos dos principais estudiosos modernos, cf., entre tantos, Gigon (1936); Calogero (2012); Zeller (1969); Diano (2007).

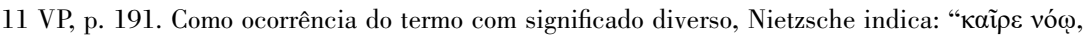

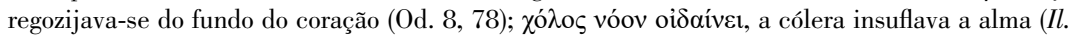

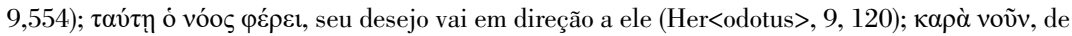
acordo com a vontade" (VP, p. 188n.). 
Busellato, S.

os comentadores interpretam mal o voũ $\varsigma^{\prime \prime 2}$. Ao contrário, e aqui se encontra um dos pontos majoritariamente originais de sua exegese, Nietzsche opera uma torsão naturalista e materialista do significado de Nous $^{13}$. Observando como Anaxágoras o atribuía também aos animais e às plantas, nega que possa ser concebido como forma de "inteligência consciente"14. O Nous, enquanto pensamento, não é nada além de matéria, "muito delicada e sutil"15. Ele se diferencia unicamente segundo a sua massa e, consequentemente, a forma que assume. Entre as formas possíveis, como caso particular, se encontra o pensamento e a inteligência ${ }^{16}$. Estes resultam ser, então, epifenômenos da matéria, tanto que, dando uma interpretação particular a uma passagem aristotélica, Nietzsche sustenta que, para Anaxágoras, o ser humano é o mais dotado de inteligência, não porque possua dotes espirituais a ele particulares, mas por razões meramente fisiológicas e morfológicas materiais, ou seja, porque é dotado de mãos ${ }^{17}$.

Dessa maneira, Nietzsche pode ler em Anaxágoras uma característica que depois será um dos pontos qualificantes também da própria Vontade de potência: pelas razões vistas, em Anaxágoras não é rastreável "uma contraposição matéria-espírito"18.

Para Nietzsche, o Nous, longe de ser um princípio metafísico racional, deve ser interpretado de modo muito mais simples como

12 VP p. 191.

13 A fórmula que Nietzsche utiliza para ilustrar Anaxágoras é "dai-me a matéria e construirei o mundo" (PHG/FT, 17, trad. de Maria Inês Madeira de Andrade; KSA 1.867).

14 VP, p. 190. Cfr. também NF-1872, 19[18]; KSA 7.422. Essa interpretação se apoia em Aristóteles, Das Plantas, I, 1, 815b 16.

15 PHG, §15; KSA 1.859.

16 Ibid.

17 VP §12, D’Iorio p. 191, "As diferenças do Nous, portanto, provêm da matéria». Cfr. Aristóteles, De part. anim., IV, 10, 687a 7 e ss.

18 NF-72,23[22]. Cfr. também os NF-1872, 21[22]; KSA 7.526: «Em Anaxágoras - não espíritomatéria»; NF-1872,19[89]; KSA 7.449. Mais tarde, Nietzsche sustentará que todos os dualismos são interpretações ilusórias que, na verdade, não são outro que a vontade de potência (Cfr., por exemplo, NF-1885,2[147]; KSA 12.139);

112 | Cad. Nietzsche, Guarulhos/Porto Seguro, v.42, n.2, p. 105-124, maio/agosto, 2021. 
movimento (Bewegung), moto circular, rotação $(\pi \varepsilon \rho \imath \chi \omega ́ \rho \eta \sigma ı \varsigma)^{19}$. E já a esta altura Nietzsche começa a fazer uso de um vocábulo que depois será central no interior do quadro da Vontade de potência: aquele de força (Kraft). O Nous, o movimento, é uma força no sentido de "uma espécie de vibração"20, é uma "força vital [Lebenskraft] que é uma em todas as coisas" $"$.

Mas não terminam aqui as referências da leitura da visão anaxagoreana à futura Vontade de potência.

O Nous, compreendido como movimento, age sobre as homeomerias ou sementes (spermata) primordiais dotando cada uma delas com uma qualidade singular. Elas se encontram em uma

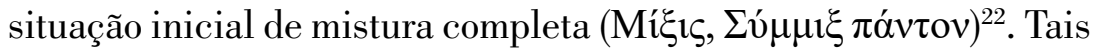
homeomerias são normalmente interpretadas como uma espécie de elementos atômicos últimos, caracterizados pela impenetrabilidade. Agora, Nietzsche refuta essa leitura, e pensa as componentes da mistura anaxagoreana mescladas umas às outras, ou seja, em um estado de "compenetração [Durchdringung] da matéria"23. Atribuir à matéria a característica da compenetração significa retirar o substrato formado por qualquer tipo de unidade estável, por mais infinitesimais que eles possam ser, e, vendo o movimento operante em tal fluidez, Nietzsche confere ao cosmo anaxagoreano uma natureza caótica e, ao mesmo tempo, dinâmica nunca tida antes. Graças a isso, ele pode falar de um modelo explicativo alternativo, seja ao mecanicismo

19 VP, p. 191.

20 Rosciglione, 2005, p. 78.

21 VP, p. 192.

22 DK-4.

23 NF-1873, 26[1], KSA 7.571: “Anaxágoras. Movimento circular. Teoria dinâmica, compenetração da matéria, p. 324"; cf. Também PHG/FT 16, KSA 1.862; 17, KSA 1.864. As notas à edição italiana do segundo volume dos fragmentos póstumos 1869-1874, p. 513, esclarecem como a referência de página que Nietzsche anota diz respeito a Hermann Kopp, Geschichte der Chemie, II, Braunschweig, 1844 (tomada em empréstimo por Nietzsche em 28 de março de 1873), sobre "pontos de vista dinâmicos" na química, que buscam "explicar os fenômenos de parentesco com uma compenetração recíproca das diversas matérias". 
Busellato, S.

(que necessita de unidades basilares), seja às soluções mágicometafísicas, que pensam a uma actio in distans ${ }^{24}$, posições estas que, para Nietzsche, poderão ambas ser superadas também mediante a hipótese da Vontade de potência.

$\S 4$. Mas se a mistura se dá em um estado de compenetração da matéria, se tal compenetração é completa (vollständiges Durcheinander) ${ }^{25}$ ("tudo está em tudo") e se esta é dinamicamente atravessada pelo Nous-movimento, o qual não encontra qualquer unidade - como surgem, então, a partir dessa mistura fluída e caótica, as qualidades e as unidades? É para buscar dar uma resposta a tal questão que Nietzsche elabora uma teoria interpretativa no interior da qual nascem alguns elementos que posteriormente reencontraremos no centro do apanhado teórico da Vontade de potência.

Segundo Nietzsche, as qualidades, em Anaxágoras, não são atributos isolados em si mesmos, não possuem uma existência autônoma. A obra do movimento sobre o caos indistinto não age, portanto, sobre unidades qualitativas preexistentes. "Anaxágoras admite apenas um $\sigma u \mu \mu i ́ \gamma \gamma \varepsilon \sigma \theta \alpha 1$ [mesclar-se] e um $\delta 1 \alpha \kappa \rho i ́ v \varepsilon \sigma \theta \alpha 1$ [separar-se]"26. Isso então significa que o Nous, conferindo movimento em um estado de indistinção, cria "relações [Verhältnis]"27. A qualidade nasce, assim, unicamente como mudança de forma, de disposição, ou seja, refere-se a nada além da

24 PHG/FT 14; KSA 1.855 Nisso reside o elemento iluminista-científico repetidas vezes destacado em Anaxágoras e contraposto, por exemplo, ao elemento presente em Empédocles cf. NF-1872,21[15]; KSA 7.527; NF-1872,23[8]; KSA 7.540 A visão anaxagoreana provém do "mais puro espírito do método pertinente às ciências naturais" (PHG/FT 19), pode-se vislumbrar "o rigor do seu raciocínio científico" (VP, p. 190).

25 PHG/FT16, KSA 1.861.

26 VP, pp. 187-88.

27 NF-1872,19[242]; KSA 7.495. No interior da elaboração da teoria da Vontade de potência, Nietzsche escreverá: "Se tiro de uma coisa todas as relações, todas as 'propriedades', todas as 'atividades', não resta a coisa, pois a natureza de 'coisa' é apenas algo de fictício acrescido por nós por exigência lógica e, portanto, com a finalidade de designar, de ser compreendido, [...] (para ligar aquela multiplicidade de relações, propriedades e atividades)" (NF-1887,10[202]; KSA 12.580).

114 | Cad. Nietzsche, Guarulhos/Porto Seguro, v.42, n.2, p. 105-124, maio/agosto, 2021. 
posição, da ordem, do reagrupamento, da mesclagem e da separação [die Stellung Ordnung Gruppirung Mischung Entmischung] [...] trata-se de algo semelhante a um jogo de dados [Wiirfelspiel]: os dados são sempre os mesmos, mas caindo ora em um modo e ora em outro modo, para nós, significam algo diferente (PHG/FT 14, KSA 1.852).

As qualidades, portanto, não são entidades fixas, mas relacionais. E tais relações, sendo derivadas do movimento, são configurações (Gestaltungen) sempre instáveis e cambiantes. Do mesmo modo, as unidades não são outra coisa que multiplicidades organizadas segundo um reagrupamento específico e momentâneo, que sofrerá novas separações, posteriores mesclagens. Isto é, as unidades qualitativas são aglomerados provisórios, e não singularidades substanciais. É o que, mais tarde, fazendo referência aos quanta de potência, Nietzsche chamará Zusammenspiel, "cada unidade é apenas uma unidade de organização e de fusão [Organisation und Zusammenspiel] [...] portanto uma formação de domínio [Herrschafts-Gebild] que significa unidade, mas não é uma coisa"28.

"A caótica compenetração do estado originário [caotischen Durcheinander des Urzustandes]"29, em Anaxágoras, é uma mistura estática de infinitos e indistintos elementos que, a partir de um certo ponto, começam a se movimentar, a formar agregações, organizações que o Nous-movimento continuará a separar e a recompor em novas agregações. Essa é, para Nietzsche, a grandeza da visão anaxagoreana. Segundo ele, essa visão foi capaz não só de explicar pela primeira vez a "pluralidade das qualidades", mas compreendeu também que "de um único ser não é possível explicar a mudança"30.

Nietzsche, nesse sentido, se posiciona contra as interpretações que tradicionalmente aproximaram Anaxágoras à doutrina eleata

28 NF-1885, 2 [87], KSA 11.104.

29 PHG/FT 17, KSA 1.864.

30 PHG/FT 14, p. 327; KSA 1.856. 
Busellato, S.

"do único ser"31 ou, ainda, ao apeiron de Anaximandro. E sustenta, ao contrário, que Anaxágoras, restitui realidade à "pluralidade, ao movimento e à infinitude" que haviam sucumbido perante a recusa parmenidian $^{32}$, refutando hipostatizar uma unidade como causa primeira - diferentemente do que havia feito Anaximandro. Da comparação entre os dois, Anaxágoras se torna, aos olhos de Nietzsche, aquele que renunciou à unidade em prol da multiplicidade e, ao ser, opôs o vir-a-ser: ele demonstra "não ter a necessidade de derivar a pluralidade da unidade, o vir-a-ser do ser"33. A teoria da Vontade de potência não dirá nada diferente disso.

$\S 5$. Seguramente, para vislumbrar, na mais que particular interpretação do pensamento anaxagoreano proposta por Nietzsche, as origens filosóficas de certas concepções que pertencerão à própria futura Vontade de potência, ainda faltariam elementos de grande importância. A começar, antes de qualquer coisa, pela sua caracterização, justamente, em termos de "potência", "domínio", bem como faltaria a dinâmica conflitual que move as relações entre os quanta de potência.

Lançando os olhos para as páginas nietzschianas dedicadas a Anaxágoras, contudo, percebe-se, não sem uma certa surpresa, como, na realidade, é possível rastrear também tais elementos. Encontram-se no interior da explicação da formação da qualidade em Anaxágoras, isto é, aquilo que, para Nietzsche, é a proposta dinâmica e multíplice com a qual Anaxágoras pensa o vir-a-ser.

Se as qualidades se formam da indistinção unicamente por meio da ação do Nous-movimento que mescla, reagrupa e separa

31 PHG/FT 15, p. 332, KSA 1.859. Veja-se o que Nietzsche repetirá anos depois: nada teve "uma mais ingênua força de convencimento do que o erro do Ser, como foi formulado, por exemplo, pelos eleatas: ele tem a seu favor cada palavra, cada frase que falamos" (GD/CI, A razão na filosofia 5; KSA, 6.78).

32 PHG/FT 15, KSA 1.858.

33 PHG/FT 16; KSA 1.864.

116 | Cad. Nietzsche, Guarulhos/Porto Seguro, v.42, n.2, p. 105-124, maio/agosto, 2021. 
sem interrupção, Nietzsche vê nisso algumas características complementares. Ele apoia-se em uma passagem da Física de Aristóteles (I,4,187b 1-9), na qual está escrito que Anaxágoras

afirma [-] que tudo está misturado em tudo, porque via [-] tudo a provir de tudo; e afirmara que < as coisas $>$ se mostram diferenciadas e se denominam de modo distinto umas das outras por aquilo que, na mistura dos <elementos> ilimitados, prevalece [vं $\varepsilon \rho \varepsilon \dot{\chi} \chi o v \tau o \varsigma]$ pela quantidade. Dado que, de maneira pura, não há um branco íntegro, nem preto, nem doce, nem carne, nem osso, mas que se reputa ser a natureza da coisa aquilo que cada <qualidade>

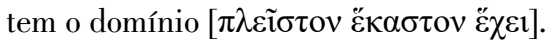

Nietzsche traduz o verbo hyperecho (valer mais, prevalecer) e a construção verbal pleiston... echei (ter a maior parte, ter o domínio) com o termo Übergewicht (domínio, prevalência). As qualidades, portanto, se formam por meio de um processo no qual aquilo que se agrega prevalece ou domina sobre outro que cede ou é dominado. Escreve Nietzsche: "se tudo pode surgir do todo [...] então tudo deve igualmente estar contido no todo. Os nomes das coisas exprimem apenas aquilo que prevalece [...] o prevalecer [Übergewicht] pode ser produzido gradualmente apenas através do movimento"34, "[este] é resultado de um processo por nós comumente chamado vir-a-ser"35. Estamos, assim, nas imediações do que, em seguida, ele denominará Kraftcentren (centros de força) ou Kraftconstellationen (constelações de força) $)^{36}$.

Como consequência desse dominar e prevalecer por meio dos quais as qualidades são formadas, o vir-a-ser de Anaxágoras toma, para Nietzsche, um sabor agonístico, altamente heraclitiano, continuamente atravessado pelo polemos (disputa, conflito).

34 PHG/FT 15, KSA 1.862

35 VP, p. 195.

36 Vejam-se os fragmentos: NF-1881,11[311], KSA 9.560; NF-1888,14[81, 98, 184, 186, 188, 211]; KSA 13.261, 274-275, 371, 375, 389. 
Busellato, S.

Anaxágoras "assume que eles [os corpos] devem disputar o mesmo espaço e que essa luta [Kampf] causa todas as mudanças"37. E, como em Heráclito, vê em Anaxágoras uma característica que posteriormente será também da própria Vontade de potência, qual seja, "a ideia de que em todo ser e em todo vir-a-ser os opostos coexistem"38. É este o "canto canônico do domínio do Nous, sobre as lutas [Kämpfen] e as leis da Physis" ${ }^{39}$.

$\S 6$. Isso tudo, entretanto, poderia se revelar ainda parcial e distante da interpretação do vir-a-ser posteriormente proposta por Nietzsche se, como interpreta a tradição, Anaxágoras atribuísse ao Nous uma natureza teleológica que conduziria à concretização de uma ordem final perfeita. Platão e Aristóteles ${ }^{40}$ moveram conjuntamente a mesma crítica a Anaxágoras: "ele deveria ter demonstrado, mas não teria, porém, demonstrado, que cada coisa - no seu método de existir e no seu lugar - existe precisamente com a máxima beleza, excelência e finalidade" ${ }^{41}$. Para Nietzsche, em vez disso, Anaxágoras explicitamente negou um caráter finalístico ao Nous, caso contrário, "este teria se tornado um ser mitológico, um deus, exatamente aquilo que Anaxágoras rejeitava" 42 .

37 PHG/FT 14; KSA 1.855. Cf. também “Anaxágoras tomou de Heráclito a ideia de que em cada ser e em cada vir-a-ser os opostos coexistem. Ele percebeu a contradição decorrente da afirmação de que um corpo possui numerosas qualidades, e pulverizou [pulverisirte] o corpo, crendo tê-lo reduzido então às suas verdadeiras qualidades" (NF-1872,23[27]; KSA 7.549).

38 NF-1872,23[27]; KSA 7.548.

39 PHG/FT 19; KSA 1.869.

40 Fed., 97c-98; Met., A 4 985a 18.

41 PHG/FT 19, KSA 1.891.

42 VP, p. 190. Leia-se também: "É sem razão que se imputa a Anaxágoras a confusão habitual dos teólogos que, maravilhados com a utilidade extraordinária do mecanismo, com a consonância das partes com o todo, nomeadamente no mundo orgânico, supõem que o que existe para o intelecto também deve ter sido introduzido pelo intelecto e que aquilo que eles só realizam com a ajuda de um conceito de finalidade também deve ser realizado pela natureza, por meio da reflexão e de conceitos de finalidade" (PHG/FT 17 - trad. de Maria Inês Madeira de Andrade; KSA 1.866). Cf. supra nota n. 5.

118 | Cad. Nietzsche, Guarulhos/Porto Seguro, v.42, n.2, p. 105-124, maio/agosto, 2021. 
Aqui está a ideia (que Nietzsche retomará na caracterização da Vontade de potência) de que o Nous-movimento é uma causa efficiens sem causa finalis ${ }^{43}$, ou seja, que não possui outro objetivo além de agir do modo como age. O Nous, escreve Nietzsche, opera "incondicionadamente, indeterminadamente, sem ser guiado por causas ou por fins" $"$. Sem possuir uma causa, sem possuir um fim, o processo anaxagoreano tampouco terá uma conclusão $o^{45}$.

O Nous, consequentemente, de nenhum modo estabeleceu uma ordem absoluta, nem uma separação perfeita, mas simplesmente um movimento por meio do qual as coisas se diferenciam com base em distinções gerais: provocou a prevalência [Übergewicht] de um tipo de matéria, nada além disso. Não se trata de um finalismo, mas apenas de movimento ${ }^{46}$.

O movimento do Nous estará, portanto, continuamente operando, e o mundo anaxagoreano eternamente mudando. A transformação é assegurada pela dinâmica da formação das qualidades, do movimento que mescla e separa.

O transformar perpétuo, porém, não reside no movimento, mas nas configurações qualitativas que se criam e se desfazem, em um processo no qual só existe o compor-se, o descompor-se, o decompor-se e o recompor-se.

Um princípio único, infinitas combinações: será encontrado também como característica das Kraftlagen (situações de força) ${ }^{47}$ da Vontade de potência. O vir-a-ser não cria o novo ex nihilo, mas produz incessantemente novas reconfigurações do existente. Escreve,

43 PHG/FT19, cf. também: "o voṽ $\sigma$ é, ao mesmo tempo, causa eficiente (causa efficiens) e causa final (causa finalis)" (VP, p. 190); KSA 1.871.

44 PHG/FT 19, KSA 1.871.

45 Nietzsche insiste sobre o caráter de incompletude do Nous anaxagoreano, por exemplo, cf. PHG/ FT 17 e 19; KSA 1.865, 870. Veja-se também Rosciglione, 2005, p. 79

46 VP, p. 196.

47 NF-1881,11[213, 232, 305]; KSA 9.525, 530, 558. Sobre isso, Müller-Lauter, 1974, p. 103.

Cad. Nietzsche, Guarulhos/Porto Seguro, v.42, n.2, p. 105-124, maio/agosto, 2021. | 119 
Busellato, S.

então, Nietzsche: "Anaxágoras descobriu a lei de conservação da energia e da indestrutibilidade da matéria"48.

$\S 7$. O fato de o Nous ser apenas causa efficiens e não possuir nem mesmo um motivo originador ou um destino final tem também outras consequências para Nietzsche.

Completando o trabalho de distanciamento das interpretações que pretendem o Nous como princípio racional e providente, Nietzsche sustenta que, a quem perguntasse por que o Nous se move, quando começa e por que o faz, "Anaxágoras responderia: 'O Nous tem o privilégio do arbitrio [das Privilegium der Willkür]"'49. Willkür (arbítrio), literalmente, vontade livre, é a tradução conceitual escolhida por Nietzsche para o atributo que Anaxágoras dá ao próprio Nous, o

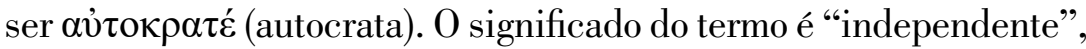

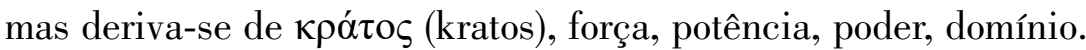
O Nous é uma força que não depende de mais nada, e a sua famosa ordem criadora é uma ondulação instável de algo de material e quantitativo que forma conjuntos de multiplicidades, as qualidades, que se constroem e se destroem incessantemente, modificando-se e remodelando-se.

Essa ordem (Ordnung) está conceitualmente muito próxima da Rangordnung (hierarquia) dos quanta de potência do último Nietzsche: hierarquia, isto é, uma ordem qualitativa, mas que nasce de uma natureza quantitativa, ou seja, simplesmente das diferentes quantidades de potência.

A arbitrariedade do Nous-movimento, portanto, diz respeito a um vir-a-ser sempre imprevisível, casual, irracional, mutável. É por

48 VP, p. 192. Nietzsche retoma expressamente Helmholtz, Abhandlung über die Wechesel-wirkung der Naturkräfte (1854), no qual fala-se de um princípio de conservação da força que é eterna enquanto, reciclando-se, transforma-se continuamente. Sobre este ponto, veja-se Rosciglione (2005), p. 81.

49 PHG/FT 19; KSA, 1.868-869.

120 | Cad. Nietzsche, Guarulhos/Porto Seguro, v.42, n.2, p. 105-124, maio/agosto, 2021. 
isso que, para Nietzsche, com o atributo da autocracia, entramos no "espaço mais sagrado que se pode descobrir no campo das ideias de Anaxágoras" 50.

O Nous não possui qualquer dever, e, por isso, não possui nenhum escopo que seja forçado a perseguir: se uma certa ocasião dá início àquele movimento e se propõem um objetivo, trata-se apenas - a resposta é difícil, mas Heráclito pode ajudar - de um "jogo" [Spiel] [...] fundando-se sempre sobre aquele arbítrio [Willkür] irracional que se esconde nas profundezas do artista. [...] "O vir-a-ser não é um fenômeno moral, mas unicamente um fenômeno artístico" ${ }^{" 51}$.

Ainda mais do que isso, o Nous, para Nietzsche, é "aquela vontade [Wille] absolutamente livre [...] [que] pode ser pensada como desprovida de fins, quase como uma brincadeira de crianças [Kinderspiel], ou como um jogo artístico [künstlerischen Spieltrieb]"52. Também a Vontade de potência será caracterizada como um jogo: Gesamtspiel (jogo global), Gegenspiel (jogo de oposições), Zusammenspiel (jogo de conjunto, interação). O jogo, a brincadeira de crianças, indica a inocência do vir-a-ser que permanecerá uma constante no pensamento de Nietzsche. $\mathrm{O}$ jogo do artista implica considerar o "mundo como [uma] obra de arte que se gera a partir de si mesma"53, do mesmo modo que está escrito em um fragmento sobre a vontade de potência.

Em outro, e um entre os mais célebres fragmentos sobre a Vontade de potência, Nietzsche escreverá:

50 PHG/FT16, KSA 1.864.

51 PGH §19; KSA 1.869

52 Ibid.

53 NF-1885,2[114]; KSA 12.119. 
Busellato, S.

Sabeis vós o que para mim é “o mundo”? Devo mostrá-lo em meu espelho? Este mundo: um monstro de força, sem começo, sem fim, uma firma, brônzea grandeza de força, que não se torna maior, não se torna menor, não se consome, só se transforma e, como um todo, é de imutável grandeza, uma administração sem gastos e sem perdas, mas, do mesmo modo, sem crescimento, sem ganhos, [...] força em toda parte, como jogo de forças e ondas de forças, ao mesmo tempo uno e múltiplo, acumulando-se aqui e ao mesmo tempo diminuindo acolá, um mar de forças tempestuosas e afluentes em si mesmas, sempre se modificando, sempre refluindo, [...] como um fluxo e refluxo de suas configurações, passando das mais simples às mais complexas, do mais calmo, mais rígido, mais frio ao mais incandescente, mais selvagem, mais contraditório e depois, de novo, do multíplice voltando ao mais simples, através do jogo das contradições até o prazer da harmonia, [...] este meu mundo dionisíaco do criar eternamente si mesmo, do destruir eternamente si mesmo, este mundo misterioso da dupla verdade, este meu "além de bem e mal", sem fim, [...] - vós quereis um nome para este mundo? Uma solução para todos os seus enigmas? Uma luz também para vós[?] [...] Este mundo é vontade de potência - e nada além disso! [...] (Nachlass/FP 1885,38[12]. KSA 11.610).

Uma visão dionisíaca do mundo, esta. Uma visão anaxagoreana.

Para compreender ainda mais a fundo a teoria nietzschiana, portanto, mesmo antes das leituras científicas e dos elementos que Nietzsche trará destas - alargando e dando precisão à própria concepção -, devemos também ver o jovem Nietzsche que, adentrandose no longínquo pensamento grego pré-socrático, e elaborando uma das interpretações mais particulares e originais dos poucos fragmentos de Anaxágoras que nos restam, já exprimia aquela própria visão de mundo, que posteriormente chamará - Vontade de potência. 


\section{In the beginnings of Will to Power: Anaxagoras}

Abstract: This article studies the Nietzschean interpretation of a pre-Socratic little considered by the secondary literature: Anaxagoras of Clazomenae. Some elements of Nietzsche's absolute interpretative originality regarding the traditional exegesis of the Greek philosopher are highlighted such as, for instance, reading the Nous in materialistic terms, the explanation of the birth of qualities from quantitative provisions or interpreting Anaxagorean homeomeries as points of force. From these and other characteristics of the Nietzschean reading of Anaxagoras, precise aspects emerge that will later be found in the theory of the Will to Power, a theory which, therefore, has, in Anaxagoras' interpretation, the very first theoretical development.

Keywords: Anaxagoras, Will to Power, ancient ontology.

\section{Referências}

BAUER, M. "Zur Genealogie von Nietzsches Kraftbegriff. Nietzsches Auseinandersetzung mit J. G. Vogt." In: Nietzsche-Studien, n. 13, 1984, p. 211-227.

CALOGERO, G. Storia della logica antica [1967], a cura di Bruno Centrone. Pisa: ETS Edizioni, 2012.

DIANO, C. Il pensiero greco da Anassimandro agli stoici. Torino: Bollati-Boringhieri, 2007.

GIGON, O. “Zu Anaxagoras”. In: Philologus, n. 41, 1936, pp. 1-14.

GORI P. La visione dinamica del mondo. Nietzsche e la filosofia naturale di Boscovich. Napoli: La Città del Sole, 2007 a.

GORI P. "Volontà di potenza e descrizione del mondo: le ragioni di una scelta terminologica", in Francisco Arena-Dolz, Luca Giancristofaro, Paolo Stellino (a cura di), Nietzsche y la hermenéutica (2 voll.). Valencia: Nau Llibres, 2007 b, pp. 511-522. 
Busellato, S.

MONTINARI, M. La volonté de puissance n'existe pas, texte établi et postfacé par Paolo D'Iorio, traduit de l'italien par Patricia Farazzi et Michel Valensi. Paris: Éditions de l'éclat, 1996.

MÜLLER-LAUTER, W. "Nietzsches Lehre von Willen zur Macht". In: NietzscheStudien, n. 3, 1974, pp. 1-60; trad. brasileira de Oswaldo Giacoia Jr., A doutrina da volontade de Poder em Nietzsche. São Paulo: Anna Blume, 1997;

MÜLLER-LAUTER, W. "Der Organismus als innerer Kampf. Der Einfluss von Wilhelm Roux auf Friedrich Nietzsche”. In: Nietzsche-Studien, n. 7, 1978, pp. 189-223

ORSUCCI, A. Dalla biologia cellulare delle scienze alle scienze dello Spirito. Bologna: Il Mulino, 1992.

ROSCIGLIONE, C. Homo natura, autoregolazione e caos nel pensiero di Nietzsche. Pisa: ETS Edizioni 2005.

STACK, G. J., "Nietzsche's Myth of the Will to Power". In: Dialogos, n. 17, 1982, pp. 27-49.

ZELLER, E. La filosofia nel suo sviluppo storico, a cura di Rodolfo Mondolfo, vol. V. Firenze: La Nuova Italia, 1969. 